\title{
Agrochemical Effects Of Plasma-Treated Wate
}

\author{
Nadezhda Petryaeva ${ }^{1}$, Maria Andrianova ${ }^{1,}{ }^{,}$, Dmitry Korotkov², Sergey Korotkov ${ }^{2}$, and Georgy Spichkin ${ }^{3}$ \\ ${ }^{1}$ Peter the Great Saint-Petersburg Polytechnic University, Politekhnicheskaya street 29, St.Petersburg, 195251, Russia \\ ${ }^{2}$ Ioffe Physical-Technical Institute of the Russian Academy of Sciences, Politekhnicheskaya street 26, St.Petersburg, 194021, Russia \\ ${ }^{3}$ Megaimpulse Ltd. Politekhnicheskaya street 28, St.Petersburg, 194021, Russia
}

\begin{abstract}
Plasma-treated water can positively influence on plants, but the effect depends on a type of plasma-generating setup. Experimental setup with rather short time of water treatment was created and biological effects of plasma-treated water produced by it were investigated. The setup generated electricdischarge low-temperature plasma in air bubbles moving through water. Electric discharges were initiated by high voltage pulses with amplitude of $\sim 30 \mathrm{kV}$ and rise front $\sim 8 \mathrm{mks}$ at frequency up to $500 \mathrm{~Hz}$. After 23 minutes of water treatment by the electric-discharge plasma increase of electric conductivity and redox potential, concentrations of nitric acid were observed in water. Treatment of pumpkin, beet and pea seeds in experimental device (together with water) stimulated their germination. Plasma-treated water alone also stimulated germination of pea and bean seeds, increased yield of fruit body mass for oyster mushroom. Allium test showed inhibition of root growth by plasma-treated water due to its low $\mathrm{pH}$, but neutralization with $\mathrm{NaOH}, \mathrm{Na} 2 \mathrm{CO} 3$ or $\mathrm{Ca}(\mathrm{OH}) 2$ eliminated this effect. The authors suppose that the created setup can be applied in local crop farms for seeds disinfection and growth stimulation.
\end{abstract}

\section{Introduction}

The low-temperature plasma induced by electric discharges has various impacts on the matter. The physical phenomena produced by plasma include flows of charged particles, electric and magnetic fields, electromagnetic radiation in ranges from ultraviolet to infrared. These impacts initiate a number of plasmachemical reactions in the media. Products of such reactions contain highly reactive particles which also influence on organic and inorganic matter and living organisms [1].

Positive effects of plasma treatment were demonstrated on plant seeds. Incubation in gas-discharge plasma increased seeds germination, growth rate, disease resistance and plant productivity [2-6]. Such treatment is a good reagent-free alternative to chemical seeds dressing.

Plasma-treated water can also influence on plants and other living objects. Firstly, short-living substances with a high reactive ability (such as atomic oxygen and hydrogen, peroxides and others) can be formed under action of plasma and then initiate reactions with other substances in the media [1]. Secondly, nitrogencontaining substances can be formed from the components of water and air under action of plasma. As a result biologically assimilable forms of nitrogen (such as nitrates and ammonium) can be present in plasmatreated water [7-8] and act as fertilisers.

The composition of water after plasma treatment depends on the parameters of the setup and regime of treatment. Created experimental plasma-generating setups can be classified by the type of electric discharge, by parameters of electric current in the media, by the shape and location of the electrodes as well as by the organization of water and air supply in the discharge chamber [1].

The duration of water treatment is also an importaint parameter characterising the setup. Different types of devices require time from minutes to about an hour to achieve the desired effect [1-7].

An experimental setup for treatment of water by electric-discharge low-temperature plasma was created in the Ioffe institute. It is based on spark discharge induced by high voltage pulses [9].

The aim of the present work is to study the biological effects of plasma-treated water on the development of plants and fungi.

\section{Materials and methods}

\subsection{Experimental setup for treatment of water by electric discharge plasma}

The experimental setup included electric pulse generator and discharge chamber. The generator produced high voltage pulses between the electrodes with amplitude about $30 \mathrm{kV}$ and rise front about 8 microseconds. The frequency of the pulses was $500 \mathrm{~Hz}$.

In the discharge chamber high-voltage pulses were applied to the electrodes that were submerged in water. The volume of water in the chamber, treated at a time,

\footnotetext{
* Corresponding author: andrianova myu@,spbstu.ru
} 
was $0.7-1.0 \mathrm{~L}$. Upflow of air between the electrodes was organized through the water with rate about $3 \mathrm{~L} / \mathrm{min}$.

Application of high voltage pulses resulted in electric breakthrough in the media. Spark discharge between the electrodes was obviously seen through the transparent walls of the discharge chamber. Water was actively mixed in the chamber under the action of shock waves, caused by the energy released into the spark-discharge channels.

In the treated media inside the discharge chamber microsecond current pulses were formed with amplitude about $400 \mathrm{~A}$ and rise front of about 150 nanoseconds. More details of the generator construction and discharge chamber are given in [9].

\subsection{Chemical analysis of water}

Tap water was used for treatment by plasma. Tap water was collected from the water supply system in the Ioffe institute. In order to avoid influences of pipes corrosion products water was collected 5 minutes after the tap was wide open. Before the experiment the collected water was left in the open 5L bottles for several hours to reach room temperature. Part of water was not treated and studied as a control sample.

Water was treated in experimental setup for 2.5-3 minutes. After the treatment water samples were collected from the discharge chamber, transported to the laboratory, stored at room temperature and analysed in 1 or 2 days after the experiment.

Electric conductivity (EC) of water (before and after plasma treatment) was measured by conductometer HI 8733 (HANNA Instruments, Austria) with measurement error $\pm 5 \%$. Measurement of $\mathrm{pH}$ was done by $\mathrm{pH}$-meter I500 (Akvilon, Russia) with measurement error $\pm 0.05 \mathrm{pH}$ units. Redox potential of water was measured by electrode DMI 140-SG with measurement error $\pm 15 \%$.

Concentrations of nitrates were measured on capillary electrophoresis analyser Capel 103R (Lumex, Russia) with measurement error $\pm 14 \%$.

\subsection{Plants and mushrooms used for testing of plasma-treated water}

Experiments were carried out on pea, beet, pumpkin and bean seeds. Pea, beet and bean seeds were purchased in the shop, pumpkin seeds were taken from a ripe fruit and dried at room temperature. Pea seeds were of the Nikitka variety, beet seeds were of Mulatka variety.

For germination seeds were laid out in Petri dishes on a cloth soaked in water, and left at room temperature. Every day the small amount of water was added to the cloth to keep it wet (plasma-treated water was added immediately after its production). Germination was studied during 6 days. The experiment with seeds of pumpkin and bean was done once with 20 seeds in one series. The experiments with beet and pea seeds were repeated 4 times, 50 seeds were taken for each series (for one type of studied water).
For the tests on mushrooms commercially available kits including oyster mushroom spores and growing soil produced by "Zolotoy Urojai" were used. Spores were mixed with soil according to the manufacturer's recommendations and were watered with tap water (control) and plasma-treated water for 3 months. For each variant of watering 5 mushroom sets were used.

Allium test was performed on the onions of Sturgarten variety according to [10]. Ten onions with mass 7-9 grams each were used for each type of water. Onion bulbs were incubated in the investigated waters to grow the roots. The roots lengths depends on the toxic or stimulating effect of water.

Each bulb was grown in $25 \mathrm{~mL}$ tube filled to the top with water. Twice a day 1-2 $\mathrm{ml}$ of water was added to each tube to compensate its use by the onion. In the first variant of the test water in tubes was not changed completely, and the root length was measured 4 days after the start of the incubation. In the second and the third variants of Allium test water was completely changed by fresh portions each day. The second variant of the test lasted for 3 days; the third variant lasted for 4 days.

\section{Results and discussion}

Chemical analysis of water before and after plasma treatment showed the following changes. Electric conductivity of water increased from $105-110 \mathrm{mkSm} / \mathrm{cm}$ (before) to $260-320 \mathrm{mkSm} / \mathrm{Cm}$ (afterAcidity of water increased and $\mathrm{pH}$ changed from 6.8-7.2 (before) to 3.53.4 (after). Such changes of EC and $\mathrm{pH}$ are typical to plasma treatment of water and they usually indicate formation of nitric acid and other substances [8, 11].

Concentration of nitrates in the studied plasmatreated waters water increased from $0.5 \mathrm{mg} / \mathrm{L}$ (before) to 20-30 mg/L (after). This data demonstrate formation of nitric acid which was partly neutralised by substances of tap water. Redox potential of water increased from 300$350 \mathrm{mV}$ (before) to 550-610 $\mathrm{mV}$ (after), showing appearance of oxidising agents in treated water. Such changes are uauslly observed when water is treated in presence of air [12]. In other situations redox potential may decrease [13].

Germination of seeds was studied using several types of their treatment:

1) seeds were incubated in tap water (control);

2) seeds were incubated in tap water, treated with plasma for 3 minutes;

3) seeds were incubated in $5 \mathrm{mg} / \mathrm{L} \mathrm{HNO}_{3}$ solution prepared on tap water (control for acid formed in plasma-treated water);

4) seeds were treated in a discharge chamber together with water for 3 minutes and then incubated in water treated with plasma for 3 minutes.

Germination started on the $3^{\text {rd }}$ or $4^{\text {th }}$ day. Data about pumpkin, bean and beet seeds (percent of germinated seeds) are summarized in Table 1. For pea seeds the results are shown in Table 2. Pea root length was additionally measured and average values are given in the Table 2 also. 
For pumpkin the first roots were observed in $20 \%$ of seeds on the 4th day of incubation in variant 4 and on the next day $80 \%$ of seeds of this variant have sprouted. In the other variants of treatment the pumpkin seeds got covered with black spots of mold and none of them germinated (see Fig.1). Growth of mold can be explained by the way of obtaining seeds. They were collected from the ripe fruit, roughly cleaned and dried at room temperature before the test without any seeds dressing. This provided favourable conditions for insemination by mold spores and their growth on the remains of plant tissues. Only seeds that underwent treatment in discharge chamber (variant 4) got rid of mold and other infections agents and were able to grow.
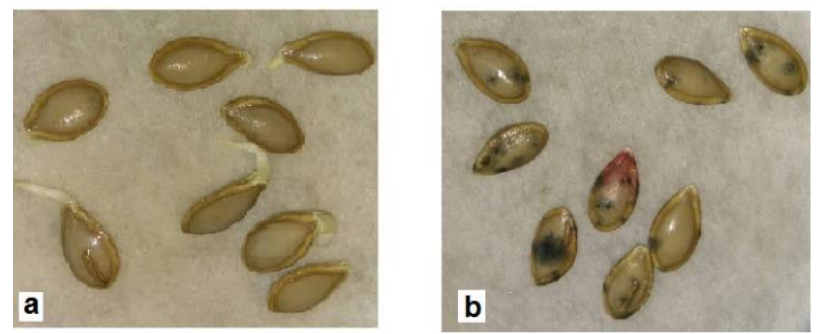

Fig. 1. Pumpkin seeds at the $5^{\text {th }}$ day of incubation: a) treatment variant 4 ; b) treatment variant 1 .

For beans the best result was also in the variant 4 . The seeds of the other variants of treatment germinated later but in variant 2 percent of seeds with root was higher than in variant 1 (control) and variant 3 (water with nitric acid).

Table 1. Variants of the composition of the beverage Maksym.

\begin{tabular}{|c|c|c|c|}
\hline $\begin{array}{c}\text { seed and variant of } \\
\text { treatment }\end{array}$ & $\begin{array}{c}\mathbf{3} \\
\text { day }\end{array}$ & $\begin{array}{c}\mathbf{4} \\
\text { day }\end{array}$ & $\begin{array}{c}\mathbf{5} \\
\text { day }\end{array}$ \\
\hline 1 pumpkin & 0 & 0 & 0 \\
\hline 2 pumpkin & 0 & 0 & 0 \\
\hline 3 pumpkin & 0 & 0 & 0 \\
\hline 4 pumpkin & 0 & $10 \%$ & $80 \%$ \\
\hline 1 bean & 0 & 0 & $30 \%$ \\
\hline 2 bean & 0 & $17 \%$ & $50 \%$ \\
\hline 3 bean & 0 & $20 \%$ & $35 \%$ \\
\hline 4 bean & 0 & $50 \%$ & $83 \%$ \\
\hline 1 beet & 0 & $43 \%$ & $93 \%$ \\
\hline 2 beet & 0 & $42 \%$ & $88 \%$ \\
\hline 3 beet & 0 & $65 \%$ & $94 \%$ \\
\hline 4 beet & $7 \%$ & $47 \%$ & $94 \%$ \\
\hline
\end{tabular}

Beet seeds showed another type of results. The earliest germination was observed in the variant 4 (the same result was for the seeds of other cultures). But at the next day the best effect (the highest number of seed clusters with one or several roots) was observed in variant 3 at lower concentration of nitric acid (compared to variants 2 and 4). At the day 5 the values became close in all variants of treatment.

For pea seeds (see Table 2) in general the results are close to those observed for beans. Comparison of variants 1-3 showed that plasma-treated water was most effective, which was expressed in an earlier beginning of germination and longer roots. This can be explained by the action of the nutrients contained in the plasmatreated water, mainly nitrates. The stimulating effect of incubation in nitric acid solution (variant 3) was more than in tap water (variant 1), but less than in plasmatreated water (variant 2). This difference could be explained by higher concentration of nitrates in plasmatreated water.

Table 2. Percent of germinated pea seeds and average root length (in $\mathrm{mm}$ ).

\begin{tabular}{|c|c|c|c|}
\hline $\begin{array}{c}\text { seed and } \\
\text { variant of } \\
\text { treatment }\end{array}$ & $\begin{array}{c}\mathbf{3} \\
\text { day }\end{array}$ & $\begin{array}{c}\mathbf{4} \\
\text { day }\end{array}$ & $\begin{array}{c}\mathbf{5} \\
\text { day }\end{array}$ \\
\hline 1 pea & $0 \%, 0 \mathrm{~mm}$ & $8 \%, 7 \mathrm{~mm}$ & $84 \%, 10 \mathrm{~mm}$ \\
\hline 2 pea & $0 \%, 0 \mathrm{~mm}$ & $71 \%, 9 \mathrm{~mm}$ & $100 \%, 19 \mathrm{~mm}$ \\
\hline 3 pea & $0 \%, 0 \mathrm{~mm}$ & $46 \%, 7 \mathrm{~mm}$ & $88 \%, 15 \mathrm{~mm}$ \\
\hline 4 pea & $20 \%, 7 \mathrm{~mm}$ & $80 \%, 14 \mathrm{~mm}$ & $100 \%, 32 \mathrm{~mm}$ \\
\hline
\end{tabular}

Variant of treatment 4 had the strongest effect on peas. Germination started 1 day earlier and on days 4 and 5 the average root length was 2-3 times longer than in the control (variant 1). This could be explained by an increase in the permeability of seed covers as a result of their pre-treatment in a discharge chamber, which facilitated water absorption and accelerated root growth [3].

The effect of plasma-treated water was also tested on oyster mushrooms. The kit for mushrooms growing included powder of mycelium and about $0.5 \mathrm{~kg}$ of soil. They were mixed together and watered with tap water (control) or plasma-treated water (experiment) during 3 months. During several days (about 1 week in a month) watering of experimental mushrooms was also done by tap water. After 3 months the fruit bodies were cut and weighted. Average mass of fruit bodies from one kit in a control was 87 grams, in experiment - 201 grams, i.e. about 2 times more.

Since the use of water enriched with nitrates can lead to their accumulation in food, the nitrates concentration in the aqueous extract of mushrooms was determined. It was $21 \mathrm{mg} / \mathrm{kg}$ in the control, $12 \mathrm{mg} / \mathrm{kg}$ in experiment. According to Russian sanitary norms for food, the content of nitrates in mushrooms is not standardized. In vegetables the maximal allowable concentration is from 60 to $500 \mathrm{mg} / \mathrm{kg}$ depending on the type of vegetables. Thus, the limits for nitrates in food products in experimental mushrooms was not exceeded.

The toxic effect of plasma-treated water was also studied in Allium test. In the test onions are put into tested water and the lengths of growing roots is measured after 3 or 4 days of incubation. Toxic compounds inhibit roots growth $[10,14]$. Three series of the test, differed by the types of water and number of days of incubation were performed. The results are shown in Tables 3-5. The types of water and their $\mathrm{pH}$ before the test are described in the first column, the $\mathrm{pH}$ of incubation media that changed during the test is given in the last column, $\mathrm{n}$ is average number of roots in one bulb, 1 is average lengths of root in the series, $\mathrm{s}$ is its standard deviation. 
Table 3. Results of Allium test, the first variant (3 days of incubation).

\begin{tabular}{|c|c|c|c|c|}
\hline water & $\mathbf{n}$ & $\begin{array}{c}\text { l, } \\
\mathbf{m m}\end{array}$ & $\begin{array}{c}\mathbf{s ,} \\
\mathbf{m m}\end{array}$ & $\begin{array}{c}\mathbf{p H} \\
\text { after }\end{array}$ \\
\hline tap water, $\mathrm{pH}=7.0$ & 55 & 20 & 9 & 6.4 \\
\hline $\begin{array}{c}\text { plasma-treated water }+ \\
\text { + NaOH, } \mathrm{pH}=8.8\end{array}$ & 63 & 25 & 12 & 7.1 \\
\hline $\begin{array}{c}\text { plasma-treated water, } \\
\text { pH=3.5 }\end{array}$ & 61 & 23 & 10 & 7.4 \\
\hline
\end{tabular}

Table 4. Results of Allium test, the second variant (4 days of incubation).

\begin{tabular}{|c|c|c|c|c|}
\hline water & $\mathbf{n}$ & $\begin{array}{c}\mathbf{l ,} \\
\mathbf{m m}\end{array}$ & $\begin{array}{c}\mathbf{s}, \\
\mathbf{m m}\end{array}$ & $\begin{array}{c}\mathbf{p H} \\
\mathbf{a f t e r}\end{array}$ \\
\hline $\begin{array}{c}\text { tap water, } \\
\mathrm{pH}=6.7\end{array}$ & 62 & 20 & 11 & 5.8 \\
\hline $\begin{array}{c}\text { tap water }+\mathrm{HNO}_{3}, \\
\mathrm{pH}=4.0\end{array}$ & 58 & 11 & 5 & $4.6-5.4$ \\
\hline $\begin{array}{c}\text { plasma-treated water, } \\
\text { pH=3.4 }\end{array}$ & 57 & 7 & 3 & $3.7-3.9$ \\
\hline $\begin{array}{c}\text { plasma-treated water }+ \\
\mathrm{NaOH}, \mathrm{pH}=6.7\end{array}$ & 67 & 17 & 9 & $5.4-5.8$ \\
\hline
\end{tabular}

Table 5. Results of Allium test, the third variant (4days of incubation).

\begin{tabular}{|c|c|c|c|c|}
\hline water & $\mathbf{n}$ & $\begin{array}{c}\mathbf{l ,} \\
\mathbf{m m}\end{array}$ & $\begin{array}{c}\mathbf{s ,} \\
\mathbf{m m}\end{array}$ & $\begin{array}{c}\mathbf{p H} \\
\mathbf{f f t e r}\end{array}$ \\
\hline $\begin{array}{c}\text { tap water, } \\
\mathrm{pH}=6.8\end{array}$ & 30 & 22 & 14 & $5.8-6.2$ \\
\hline $\begin{array}{c}\text { tap water }+\mathrm{HNO}_{3}, \\
\mathrm{pH}=3.6\end{array}$ & 12 & 4 & 2 & $3.7-3.8$ \\
\hline $\begin{array}{c}\text { tap water }+\mathrm{Ca}(\mathrm{OH})_{2}+ \\
\text { + } \mathrm{HNO} 3, \mathrm{pH}=6.8\end{array}$ & 33 & 20 & 12 & $6.1-6.4$ \\
\hline $\begin{array}{c}\text { plasma-treated water, } \\
\mathrm{pH}=3.5\end{array}$ & 14 & 4 & 2 & $3.8-3.9$ \\
\hline $\begin{array}{c}\text { plasma-treated water }+ \\
\mathrm{Ca}(\mathrm{OH})_{2}, \mathrm{pH}=6.8\end{array}$ & 32 & 19 & 10 & $5.4-6.0$ \\
\hline $\begin{array}{c}\text { plasma-treated water }+ \\
\mathrm{Na} 2 \mathrm{CO}, \mathrm{pH}=6.7\end{array}$ & 29 & 16 & 9 & $6.2-6.6$ \\
\hline
\end{tabular}

In the first variant of Allium test water was not totally replaced in the incubation tubes and only small portions were added each day. Consequently, the $\mathrm{pH}$ of water changed after incubation and the values were in the narrow range near neutral from 6.4 to 7.4 (see table 3). It can be supposed that in this variant of test $\mathrm{pH}$ of water did not significantly influence on the roots growth. The best result by the number of roots (n) and average root length (1) was shown in neutralized plasmatreated water. However, the difference was not significant and the values of 1 were within the frames of standard deviation ( $\mathrm{s}$ ).

In the second variant of Allium test the inhibiting effect of low $\mathrm{pH}$ on root growth is clearly observed. In acidified tap water and plasma-treated water the root length was approximately 2 times smaller than in other waters. The root lengths in tap water and neutralized plasma-treated water were close.

In the third variant approximately the same results were observed in several types of water: tap water; tap water with nitric acid (in concentration close to those in plasma-treated water) and calcium hydroxide, neutralizing it; neutralized plasma-treated water.
In general all variants of Allium test showed that plasma -treated water can produce inhibiting effect on root growth due to low $\mathrm{pH}$. Neutralization by $\mathrm{NaOH}$, $\mathrm{Na}_{2} \mathrm{CO}_{3}$ or $\mathrm{Ca}(\mathrm{OH})_{2}$ eliminates this effect.

\section{Conclusions}

Possible applications of experimental setup for water treatment by electric discharge low-temperature plasma were studied. The spark discharge was induced in the media (water with air bubbles) by high voltage pulses with amplitude of $\sim 30 \mathrm{kV}$ and rise front $\sim 8 \mathrm{mks}$ at frequency up to $500 \mathrm{~Hz}$. As a result microsecond electric current pulses were formed in the treated media with amplitude about $400 \mathrm{~A}$ and rise front of about 150 nanoseconds.

Treatment of seeds of pumpkin, bean and pea in the discharge chamber (together with water) accelerated their germination and prevented mold growth.

After the treatment of tap water with plasma its electric conductivity increased from 105-100 to 260-320 $\mathrm{mkSm} / \mathrm{cm}, \mathrm{pH}$ decreased from $6.8-7.1$ to 3.4-3.5, concentration of nitrates increased to $20-30 \mathrm{mg} / \mathrm{L}$, redox potential increased up to $610 \mathrm{mV}$.

Plasma-treated water accelerated germination of seeds of bean and pea compared to tap water. Watering of oyster mushroom mycelium with plasma-treated water increased the fruit body mass.

Plasma-treated water showed inhibiting effect on onion roots growth due to its low $\mathrm{pH}$. Neutralization of water with $\mathrm{NaOH}, \mathrm{Na}_{2} \mathrm{CO}_{3}$ or $\mathrm{Ca}(\mathrm{OH})_{2}$ eliminated this effect.

The created setup can be applied in local crop farms for seeds disinfection and growth stimulation. Its advantage over several other setups for plasma-treatment is in relatively high volume of treated water (about $1 \mathrm{~L}$ ) and short period of treatment (2-3 minutes).

\section{References}

1. Advanced oxidation processes for water treatment, fundamentals and applications (IWA Publishing, 2018)

2. M. Selcuk, L. Oksuz, P. Basaran, Bioresource Technol., 99, 5104 (2008)

3. E. Bormashenko, R. Grynyov, Y. Bormashenko, E. Drori, Sci. Rep., 2, 741 (2012)

4. Z. Zhou, Y. Huang, S. Yang, W. Chen, Sci. Res., 2 (1), 23 (2011)

5. B. Peethambaran, J. Han, K. Kermalli, J. Jiaxing, G. Fridman, Plasma Med., 5 (2-4), 87 (2015)

6. J. Zheng, Sci. Rep., 7 (1), 10311 (2017)

7. F. Judée, S. Simon, C. Bailly, T. Dufour, Water Res., 133, 47 (2018)

8. S. Preis, I. Panorel, S. L lauger Coll, I. Kornev, Ozone: Sci. Eng., 36 (1), 94 (2014)

9. S.V. Korotkov, M.Y. Andrianova, A.K. Kozlov, D.A. Korotkov, G.L. Spichkin, Instruments and Experimental Techniques, 62 (4), 562 (2019) 
10. G. Fiskesjö, Environ. Toxicol. Water Qual., 8 (3), 291 (1993)

11. A.A. Belov, A.N. Vasilyev, A.A. Musenko, Indonesian Journal of Electrical Engineering and Informatics, 7 (3), 422 (2019)

12. X. Sua, Y. Tian, H. Zhou, Y. Li, Z. Zhang, B. Jiang, B. Yang, J. Zhang, J. Fang, Appl. Environ. Microbiol., 84 (9), e02836-17 (2018)

13. T. Miyahara, M. Oizumi, T. Nakatani, T. Sato, AIP Advances., 4, 047115 (2014)

14. M. Iqbal, M. Abbas, J. Nisar, A. Nazir, A.Z. Qamar, Chemistry International., 5 (1), 1 (2019). 